\title{
CONTRIBUIÇÃO DA TEORIA ATOR-REDE PARA COMPREENSÃO DO PARADOXO DA GESTÃO ESTRATÉGICA DE CUSTOS
}

Simone Alves da Costa ${ }^{1}$

Beatriz Fátima Morgan ${ }^{2}$

Resumo: O objetivo deste estudo é analisar a contribuição dos conceitos da Teoria Ator-Rede (TAR) à construção da Gestão Estratégica de Custos (GEC) enquanto arcabouço teórico e área de pesquisa. Observa-se no atual momento da GEC que, apesar de ser considerada uma ferramenta de potencial incremento à competitividade, tem visto seu campo de estudo diminuir ao longo do tempo, além de ser alvo de contestações relacionadas ao seu framework, fatores que podem ser chamados paradoxais. Nesse contexto, entende-se que a TAR representa uma concepção teórica e prática que possibilita investigar essas questões, uma vez que traz conceitos que auxiliam potencialmente na compreensão das relações entre os atores e os mecanismos de construção de rede. A partir de estudos que abordam a prática da GEC, mais especificamente, seus instrumentos, por meio de conceitos da TAR, foi possível inferir proposições para futuros estudos. Primeiro, profissionais e acadêmicos poderiam estar tratando os instrumentos da GEC como se fossem munidos de funções intrínsecas, que independentemente das associações se manifestariam. Segundo, a filosofia da GEC carrega em si a sua contribuição para o futuro. Porém, a TAR mostra a instabilidade e variabilidade da construção dos fatos da rede da GEC, o que questiona a capacidade de se antecipar o futuro. Tais pontos poderiam também ser empecilhos à construção do coletivo, base para solidificação da GEC como área de pesquisa. Assim, sendo o movimento construído basicamente por mecanismos retóricos, há dificuldade em angariar visibilidade e convergência aos participantes da rede. Sugere-se a utilização deste arcabouço para a realização de pesquisas empíricas ou sua aplicação a outros fenômenos da Contabilidade Gerencial.

Palavras-chave: Teoria Ator-Rede. Gestão Estratégica de Custos. Rede. Área de pesquisa.

\footnotetext{
'e-mail: simone.ac@gmail.com - Trevisan Escola de Negócios

2e-mail: beatrizmorgan@unb.br - Universidade de Brasília

- Uma primeira versão deste trabalho foi apresentada no XV Congresso USP de Controladoria e Contabilidade, 2015

- DOI: http://dx.doi.org/10.14392/asaa.2017100201

- Artigo submetido em: 14/03/2016. Submetido a nova rodada em: 20/11/2016. Aceito em: 14/04/2017.
} 


\title{
CONTRIBUTION OF ACTOR-NETWORK THEORY FOR UNDERSTANDING THE PARADOX OF STRATEGIC COST MANAGEMENT
}

\begin{abstract}
The objective of this work is to analyze the contribution of the concepts of the Actor-Network Theory (TAR) to the construction of Strategic Cost Management (SCM) as a theoretical framework and research area. It is observed in the current SCM moment that, despite being considered a potential tool to increase competitiveness, it has seen its field of study decrease over time, besides being the target of contestations related to its framework, factors that can be called paradoxical. In this context, it is understood that the TAR represents a theoretical and practical conception that makes it possible to investigate these issues, since it brings concepts that help potentially in the understanding of the relations between the actors and the mechanisms of network construction. From the studies that approach the practice of SCM, more specifically, its instruments, through concepts of ART, it was possible to infer propositions for future studies. First, practitioners and academics could be treating SCM instruments as having intrinsic functions that would manifest themselves independently of associations. Second, SCM's philosophy carries within itself its contribution to the future. However, the TAR shows the instability and variability of the construction of the facts of the SCM network, which questions the ability to anticipate the future. Such points could also be obstacles to the construction of the collective, basis for solidification of GEC as a research area. Thus, being the movement basically constructed by rhetorical mechanisms, it is difficult to raise visibility and convergence to the network participants. We suggest the use of this framework for conducting empirical research or its application to other phenomena of Managerial Accounting.
\end{abstract}

Keywords: Actor Network Theory. Strategic Cost Management. Network. Research Field. 


\section{INTRODUÇÃO}

$\mathrm{N}$ este estudo discute-se o aparente paradoxo que envolve a Gestão Estratégica de Custos (GEC): Por que, aparentemente, a temática que envolve a GEC parece diminuir no que tange à sua atuação $e$ visibilidade, se informações de custos, que (supostamente) deveriam prover apoio à tomada de decisões e controles gerenciais, são relevantes para promover a competitividade e desempenho das empresas?

Se por um lado, nota-se que em mercados competitivos há adoção de melhores práticas gerenciais (Bloom \& Reenen, 2010), das quais a gestão da estratégia e de custos faz parte, por outro, o estudo da Ernst \& Young e IMA (2003) mostrou que os gestores tendem ainda a adotar ferramentas tradicionais de gestão e mensuração de custos em detrimento às técnicas mais contemporâneas, sendo que tais ações não estão na lista de prioridades das empresas e, quando ocorrem, são mais relacionadas a práticas orçamentárias e implantação de ERPs (Enterprise Resource Planning). Nesse caso, o orçamento e os ERPs poderiam estar absorvendo um tempo adicional, que retiraria atenção de outras partes que envolvam a administração, como a gestão de custos.

Na década de 1980, a Contabilidade Gerencial (CG) foi alvo de críticas sobre a perda de relevância e de utilidade do ferramental utilizado em suas análises (Johnson \& Kaplan, 1987). A GEC é uma das respostas a esse movimento. Para El Kelety (2006), a GEC é uma filosofia munida de técnicas que ajuda a nortear a definição do futuro da empresa, focando não apenas em custos, mas em itens como receita, produtividade e valor adicionado ao cliente. Conceitualmente, a GEC é compreendida sob diferentes prismas: como um framework ou filosofia de gestão (El Kelety, 2006; Anderson \& Dekker, 2009), como um conjunto de técnicas gerenciais, tais como o Custeio Baseado em Atividades, a Gestão da Qualidade Total, o Custeio Alvo (Cooper, 1997; Afonso, 2007), ou ainda, como um sistema de informação que administra a gestão de custos de uma organização (El-Dyasty, 2007). A concepção de GEC utilizada neste trabalho entende que ela é composta por filosofias, atitudes e artefatos para gestores que buscam melhorias em custos, bem como competitividade e valor agregado ao ambiente da empresa (Borges Slavov, 2013).

No entanto, a GEC é alvo de críticas no que diz respeito à estrutura teórica incipiente (El Kelety, 2006), pouca interdisciplinaridade (Ellram \& Stanley, 2008), resistência dos profissionais da área de contabilidade gerencial e, principalmente, rejeição como objeto de pesquisa na academia (Shank, 2006). Tais críticas, apesar de terem fundamento, são muito simplistas se considerarmos que a contabilidade faz parte de uma complexa estrutura social (Lowe, 2001). Mais do que conceitos, relatórios, princípios e artefatos, ela é produto de interesses do meio (Meira, Kartalis, Tsamenyi, \& Cullen, 2010). Joannides e Berland (2013) argumentam que não existe preocupação em entender como o conhecimento contábil é produzido. Eles afirmam que não se sabe como a comunidade de pesquisa contábil trabalha, tampouco como a rede acadêmica emerge e evolui. Logo, eles afirmam que, não havendo papers lidando com a ontologia da produção do conhecimento, existe espaço para o entendimento de como ele é desenvolvido, estabelecido e a forma de construção nas redes de conhecimento contábeis.

Na literatura relacionada à contabilidade, há pouca ênfase em estudos empregando métodos voltados à sociologia, psicologia e áreas correlatas, metodologias diferenciadas em relação às tradicionalmente aplicadas no ambiente contábil (Baxter \& Chua, 2003; Chua, 2011). No entanto, Brignall (2007) aponta 
que o uso de diferentes abordagens metodológicas, bem como a análise das mais apropriadas de acordo com o problema de pesquisa, é desejável na pesquisa em CG. Desse campo de estudos emerge a TAR (Teoria Ator-Rede, do inglês Actor-Network Theory), cuja ideia central é discutir os atores como efeitos das redes as quais pertencem (Latour, 2000). Ela ainda destaca a influência que os atores não humanos (sistemas, periódicos, livros etc.) podem ter no processo de criação do coletivo (Latour, 2000, 2006), o que pode determinar a evolução (ou não) de uma área, artefato, implantação etc.

A TAR procura descrever como os fatos acontecem, tentando entender as origens do poder e da estrutura de uma rede por meio dos processos colaborativos, cooperativos, competitivos e de negociação em que os atores estão inseridos (Hui, 2012). Outro ponto que a TAR analisa é a produção do conhecimento, ao observar a rede em que vários tipos de atores interagem para seu estabelecimento, avanço e desenvolvimento (Joannides \& Berland, 2013)

Até o momento, a TAR não tem seu uso expandido dentro da pesquisa em Contabilidade, apesar de estar crescendo ao longo dos anos (Zawawi \& Hoque, 2010). Ela permite descrever efeitos que não podem ser captados por outras teorias sociais (Latour, 2006), como a teoria da contingência e a teoria institucional, mais comuns nos estudos da área (Justesen \& Mouritsen, 2011; Lowe, 2001), o que é válido no sentido de garantir perspectivas multiteóricas para a pesquisa em Contabilidade. Durante esta pesquisa foram encontrados poucos estudos que mesclassem GEC e TAR (Mouritsen, 1999; Jones \& Dugdale, 2000, 2002; Briers \& Chua, 2001; Alcouffe, Berland, \& Levant, 2008; Emsley, 2008; ), entendendo-se a GEC aqui do ponto de vista dos seus artefatos (Afonso, 2007; Cooper, 1997).

Diante das críticas direcionadas à GEC, que apesar de incipientes são o ponto de partida deste estudo, este estudo tem por objetivo elucidar o que faz com que o paradoxo posto seja continuamente construído, principalmente no que tange a compreender a construção da GEC como área de pesquisa. Para tanto, será analisada a contribuição dos conceitos da Teoria Ator-Rede à construção da Gestão Estratégica de Custos enquanto arcabouço teórico e área de pesquisa.

Como contribuição, este estudo sistematiza o conteúdo da TAR ao ambiente da Gestão Estratégica de Custos, sendo que o ferramental por ela elucidado pode ser útil à compreensão dos mecanismos de construção dessa rede ou de outras dentro do meio contábil. Adicionalmente, seu uso pode ser uma abordagem complementar para fins de triangulação com outras teorias comumente utilizadas na área, como a teoria da contingência e a teoria institucional (Lowe, 2001; Justesen \& Mouritsen, 2011), tendo em vista que todas elas têm estudado os mesmos objetos, porém, cada uma capta diferentes nuances da realidade. Ainda, entende-se que a melhor compreensão da rede que dissemina a GEC pode vir a colaborar com a evolução da área em termos de ensino e pesquisa, se entendidos os seus pontos fortes, bem como as suas necessidades.

\section{REFERENCIAL TEÓRICO}

\subsection{GESTÃO ESTRATÉGICA DE CUSTOS}

Foi por meio de Shank e Govindarajan (1997) que o entendimento da Contabilidade Gerencial Estratégica (CGE) moveu-se para uma GEC, fortemente influenciada pelos estudos de Porter (1985). Anderson (2006) sugere que tanto empresas quanto acadêmicos necessitavam expandir sua área de atuação naquele período, ambiente que favoreceu a GEC. Não se deve, no entanto, confundir os termos. A CGE estaria mais ligada a criar artefatos de mensuração contábil para auxiliar gestores em processos de tomada de decisão, enquanto a GEC estaria atrelada ao processo decisório. De forma geral, a GEC 
envolve iniciativas que voltem seu olhar à vertente dos custos que tenham direto impacto na estratégia, podendo ser operacionalizadas por meio de artefatos, a fim de facilitar a gestão e o controle de tais custos.

A GEC surgiu para suprir uma demanda da Contabilidade Gerencial em função do que foi chamado na época de "Relevância perdida" (Relevance Lost) da obra de Johnson e Kaplan (1987). A argumentação dos autores aponta que os pesquisadores se baseavam em modelos de tomada de decisão simplificados, datados do início do século XX, em que a empresa produzia um ou poucos produtos e tinha apenas um estágio no processo produtivo, na maior parte das vezes concebendo tais modelos por dedução ou lógica e sem estudar a complexa realidade das firmas. Porém, o que aconteceu foi que a transformação empresarial ocorrida no final do mesmo século tornou tais modelos pouco relevantes diante da realidade das organizações. Além disso, eles não identificaram inovações na Contabilidade Gerencial no período entre os anos 1955 e 1980.

A GEC então surgiu trazendo os conceitos de estratégia para dentro da Contabilidade Gerencial. Segundo McNair et al. (2001), a GEC propõe um modelo que liga custos e criação de valor, vinculando as estruturas de custos da empresa aos atributos de valor do produto. A vantagem competitiva viria da relação entre preço, custos e valor do cliente.

Conforme El Kelety (2006), a GEC tem um papel fundamental em determinar o futuro da empresa, porque promove a ideia de encontrar, de forma contínua, maneiras de ajudar as organizações a tomar decisões para criar mais valor ao cliente a um custo mais baixo. Ainda, segundo o autor, a GEC propõe alguns conceitos, tais como: orientação ao mercado, visão holística, abordagem antecipatória (visando influenciar a posição de custo futuro), continuidade (necessidade permanente de melhorias, de forma contínua), participação (requer o envolvimento de todos) e integração (das funções de negócios). O autor também define a GEC a partir de suas técnicas, que serviriam para apoiar uma meta específica ou em conjunto (mais de uma técnica) e, com isso, atender às necessidades gerais da organização. Da união de técnicas nasceria o "sistema de gestão estratégica de custos". Em geral, esse sistema deveria ser flexível o suficiente para fornecer qualquer informação desejada, em qualquer formato desejado e a pedido de qualquer pessoa autorizada na organização. No entanto, a construção e manutenção desse sistema podem ser inviáveis, fazendo com que as organizações optem por um sistema simples e econômico, que atenda suas necessidades de forma geral.

Shank (1989) colocou a GEC como um tipo de paradigma que, se bem documentado, poderia influenciar o pensamento coletivo, tal como já havia acontecido com outros modelos da própria Contabilidade Gerencial. O autor pontua que a GEC se diferenciava do paradigma contábil vigente até aquele momento por não olhar apenas produtos, clientes e funções, mas analisar os vários estágios da cadeia de valor do qual a empresa faz parte. Além disso, ela teria foco não apenas interno, mas também, externo, estando fortemente vinculada à estratégia da empresa. Todavia, ele esclarece que para que a GEC de alguma forma tomasse o lugar do paradigma vigente, seriam necessárias mudanças, tanto no processo de implantação de algumas ferramentas (tais como o $A B C$ ), como nos conceitos, sendo alguns tidos como novos (ex. custo da qualidade) ou completamente divergentes do paradigma vigente (ex. custo total preferível ao custo variável).

No entanto, parece ainda não ser claro o framework que compõe a GEC (El Kelety, 2006; Langfield-Smith, 2008), alegando-se a natureza exploratória em que ainda se encontram os estudos sobre o tema (El Kelety, 2006). Se é fato que a GEC encontra-se em estágio exploratório, talvez seja aceitável que haja incertezas no que tange à composição de seu arcabouço, bem como ao estágio de desenvolvimento dos estudos, dado que a pesquisa nessa fase ainda busca um conhecimento maior do fenômeno. 
Para entender o estágio de desenvolvimento em que se encontra a pesquisa em GEC, é importante retomar o pensamento de autores como Shank (2006), que coloca situações que vão desde a inoperância da rede de pesquisadores e associações de classe até a não prioridade do assunto nas searas profissionais. Embora não seja uma pesquisa de campo, a reflexão proposta pelo autor provoca um repensar da GEC.

No ensaio de Shank (2006) são destacados pontos como: baixa utilização das práticas de custos pelas empresas; questões deficitárias relacionadas à formação profissional em custos; fraco uso da informação de custo como ponto de apoio ao processo decisório; utilização de práticas de custos por outras áreas que não necessariamente envolvam a CG; perda de espaço do tema GEC na prática; e diminuição de estudos relacionados nas pesquisas da área.

Na sequência, são apresentados alguns estudos teóricos e práticos que versam sobre as questões levantadas por Shank (2006). Em geral, esses estudos corroboram as conjecturas do autor sobre utilidade da GEC, formação profissional, perda de espaço do tema, etc.

Por exemplo, sobre a utilização das práticas de custos pelas empresas, Dugdale et al. (2006), pesquisando companhias de manufatura do Reino Unido, constataram que elas têm preferido técnicas de custeio mais simples, como margem de contribuição e, no geral, tendem a adotar as que são tidas como as melhores práticas para realizar suas análises. Práticas de orçamento e previsão são bem consolidadas nas companhias estudadas, ao contrário do ABC (Activity Based Costing, traduzido por Custeio Baseado em Atividades), que não teve adesão nas indústrias e teve baixa aderência nas empresas prestadoras de serviços analisadas.

Já a pesquisa da Ernst \& Young e IMA (2003) cita o baixo nível de comprometimento dos gestores como uma das principais causas de insucesso na implantação de novas ferramentas de custos nas empresas. Além disso, quando implementadas, sobressaem práticas relacionadas a áreas operacionais, argumento corroborado pelos estudos de Chenhall (2008) e Heckmann et al. (2009). Bhimani e Gosselin (2009) destacam a preferência por ferramentas tradicionais de custos, informação também citada no estudo de Dugdale et al. (2006).

Sobre questões relacionadas à formação profissional em custos, Böer (2000) e Bjørnenak (2000) comentam sobre o baixo suporte que o ensino de Ciência Contábil dá ao processo de tomada de decisão. Haveria um desalinhamento entre a academia e o mercado, fato corroborado pelas pesquisas de Tan, Fowler e Hawkes (2004) e Ekbatani e Sangeladji (2008); e no que tange aos assuntos de interesse dos livros (Böer, 2000; Hoffjan \& Wompener, 2006).

Sobre o uso da informação de custo como ponto de apoio ao processo decisório, um ponto levantado nas conjecturas de Dugdale et al. (2006) é a amplitude do staff envolvido em processos de custos, não se limitando aos profissionais contábeis. Essa percepção também é compartilhada por Anderson (2006), que acredita que a GEC não está limitada aos profissionais de CG, mas permeia toda a organização. Sendo assim, justamente por não estar confinada ao espaço ou aos profissionais da área contábil, é que ela pode estar sendo realizada com sucesso em algumas organizações.

Evidência contrária tem sido descrita até aqui sobre o caminho que a GEC tem percorrido na CG, o que pode sinalizar que, em algum ponto do tempo, o profissional contábil perdeu o tempo de resposta ao que era relevante e necessário aos processos decisórios. Chenhall (2008) também afirma que outras áreas como Recursos Humanos, Tecnologia da Informação, Marketing, Produção, se definem estrategicamente com mais facilidade e é onde está a essência da GEC.

A visão da área com baixo potencial de apoio ao processo decisório também é apresentada no estudo de Heckmann et al. (2009), onde os executivos entrevistados sobre mecanismos de resposta à crise mostraram maior foco em medidas tradicionais e operacionais de custos. 
Além de outras áreas e profissionais que potencialmente podem estar envolvidos na GEC, é preciso destacar que os temas que dela fazem parte podem ter perdido espaço para outros, como é o caso do Balanced Scorecard, Ativos intangíveis e Valor Econômico Adicionado (Ittner \& Larcker, 2001); ou tecnologia da informação, ERPs, risco, gestão de fraudes e Lei Sarbanes-Oxley (Shank, 2006).

Sobre a perda de espaço do tema GEC na prática, há evidências de que isso não é exclusividade da GEC, mas sim, um problema enfrentado pela área de CG como um todo (Qu, 2006; Berland, Joannides, \& Levant, 2010) e, por consequência, também afeta as práticas de custos relacionadas à estratégia (Briers \& Chua, 2001; Bhimani \& Gosselin, 2009). Langfield-Smith (2008) argumenta que os artefatos da GEC não tem plena compreensão por parte dos profissionais ou empresas; mesmo assim, acabam exercendo potencial influência sobre o rumo dos negócios.

Sobre a diminuição de estudos relativos ao tema GEC nas pesquisas, especialmente considerando o acervo da CG, na revisão de Zawawi e Hoque (2010) sobre as inovações na área utilizando os 22 principais journals, foi verificado que pesquisas em temas como Gestão baseada em valor, Benchmarking, Custeio do ciclo de vida e Custeio alvo têm recebido pouca atenção.

Por meio dos estudos mencionados, nota-se que as pesquisas vêm de certa forma reforçando as percepções de Shank (2006), mesmo que se referindo aos assuntos abordados de forma periférica ou pontual.

Possivelmente um dos maiores problemas enfrentados pela GEC atualmente é que, por não ter um framework consistente (El Kelety, 2006; Langfield-Smith, 2008), as pesquisas são dispersas e abordam temas diferentes, que nem sempre são necessariamente atribuíveis ao ponto de vista estratégico de custos, limitando-se, em muitos casos, a práticas de mensuração ou de gestão operacional de custos. Tais abordagens não constituem nenhum demérito à pesquisa da área de custos como um todo, mas dificultam o desenvolvimento da GEC.

\subsection{TEORIA ATOR-REDE}

A Teoria Ator-Rede veio de estudos da ciência e da tecnologia, sendo seus principais autores Bruno Latour, Michel Callon e John Law (Gao, 2005). Segundo Justesen \& Mouritsen (2011), o livro Ciência em Ação é o mais utilizado nos estudos contábeis, onde são explorados os principais conceitos que a abordagem propõe (Latour, 2000).

Pensando na aplicabilidade da abordagem da TAR aos estudos em contabilidade, e aqui especialmente à GEC, nota-se que a teoria de Latour foi uma das sete alternativas mencionadas para a pesquisa em CG, em revisão dos estudos da área na Accounting, Organization and Society por Baxter e Chua (2003). Os autores consideram que o uso dessas abordagens aumenta a consideração da interdisciplinaridade na pesquisa em CG, bem como pode sustentar coibuições distintas no futuro.

\subsubsection{Principais conceitos}

Um dos primeiros conceitos de que trata a TAR são os atores, que são os participantes da rede, ou seja, todos aqueles que de alguma forma auxiliam a compor um fato e interagem no ambiente social, influenciando diretamente a concepção e propagação de um assunto. Dentro desse processo, os atores a serem considerados são aqueles que de alguma forma acrescentam algo à descrição ou à explicação. Os efeitos das ações conjuntamente irão definir a competência de um ator. E é essa competência a razão do ator agir de determinada forma (Latour, 2001, 2006).

Segundo Latour (2001), os atores podem ser humanos ou não humanos (actants ou atuantes). Os 
actants podem ser cálculos, resultados de experimentos ou quaisquer outros meios utilizados para disseminar um conhecimento na rede. $O$ autor pontua que "... quando aprendemos alguma coisa sobre o controle de humanos, transferimos esse conhecimento a não humanos, dotando-os de mais e mais propriedades organizacionais" (Latour, 2001, p. 238). Ele ainda sugere que um não humano é um ator que está por trás de humanos anônimos (Latour, 2005). A união de atores humanos e não humanos constrói o coletivo (Latour, 2001).

Outro conceito importante é o de translação. Latour (2000, p. 178) afirma que a translação é "... a interpretação dada pelos construtores de fatos aos seus interesses e aos das pessoas que eles alistam". Em outras palavras, "transladar interesses significa, ao mesmo tempo, oferecer novas interpretações desses interesses e canalizar as pessoas para direções diferentes" (Latour, 2000, p. 194). A ideia é combinar interesses até então divergentes em um único e novo objetivo composto (Latour, 2001), ou seja, é a "... criação de um vínculo que não existia e que, até certo ponto, modifica os dois originais" (Latour, 2001. p. 206).

Das translações surge a Inscrição, que Latour (2001, p. 350) conceitua como tipos de transformação que se materializam de alguma forma. Latour (2000) apresenta o conceito de inscrições, usando o exemplo dos navegadores. A inscrição seria todo o material ou descritivo encontrado na viagem, de forma a torná-la dotada de sentido. Um exemplo de inscrição são as quantificações em contabilidade que, segundo Robson (1992), permitem a ação à distância. As inscrições são móveis, estáveis ou combinadas, e aceleram o controle à longa distância, favorecendo as ações em rede.

As inscrições ampliam a mobilidade ou imutabilidade dos rastros da rede. Assim, o que é considerado verdade para a rede não é um novo ponto de vista, mas sim, o anterior no qual os objetos visíveis tem movimentação distinta no tempo e no espaço. Para Latour (1986), a inscrição é o processo final de mobilização que acaba por modificar a retórica. Latour (2004) concorda com os construtivistas no ponto em que as realidades dependem de muitas mediações, que são compostas de ingredientes heterogêneos e tem muitas histórias. A realidade é construída sob essa égide, porém, para que se mantenha, necessita de reparo constante. "Nas ciências, o grau de objetividade e certeza é diretamente proporcional ao grau de artificialidade, camadas, heterogeneidade, multiplicidade e complexidade das mediações" (Latour, 2004, p. 458). A mediação significa que um evento ou ator não são definidos pelo que consomem ou produzem, mas sofrem influência de ações provocadas (Latour, 2001). Assim, os agentes de um processo podem ser atores de fato, no sentido de realizar mediações, ou meros intermediários dos eventos.

Neste sentido que Latour (2001) propõe o conceito de programa de ação na construção do coletivo. Programa de ação consiste numa sequência de objetivos, passos e intenções que um agente pode descrever em uma narração. Sendo que o agente pode ser humano ou não humano. Assim, o agente 1, que pode ser uma tecnologia contábil, antecipa o que o agente 2, que pode ser um decisor, pode fazer. Caso haja sinergia entre ambos, gerará um terceiro agente que corresponde à fusão de ambos. Porém, essa antecipação pode não ocorrer caso o agente 2 possua outro programa, outros objetivos, o que nesse contexto se denomina antiprograma.

Nem sempre os atores envolvidos compartilham de total sinergia. Isso porque o movimento executado por uma ação gera uma série de práticas que somente apresentam perfeito equilíbrio se a função mediadora de todos os actantes mobilizados no processo for respeitada (Latour, 2001). A mediação, ao contrário da intermediação, transforma o significado dos elementos que carrega. Com isso, o input nem sempre é um bom preditor do output (Latour, 2005). Não havendo equilíbrio, o agente precisa retornar à primeira tarefa, remover o obstáculo e alcançar o objetivo. Esse subprocesso é chamado de subprograma (Latour, 2001). 
À medida que vai sendo gerado um todo organizado, obtendo-se uma coesão, aparece a caixapreta: "fato plenamente aceito ou objeto não-problemático" (Latour, 2000, p. 216). Segundo o autor, ela se move no tempo e no espaço, e se torna duradoura por meio da ação de muitas pessoas, pois se não houver quem a adote, ela irá desaparecer, mesmo que muita gente a tenha usado antes. Isso é uma observação relevante, pois nem sempre serão as mesmas pessoas que alimentarão esse processo, o que reforça a importância de um trabalho contínuo para a manutenção da rede e de seus elementos constitutivos.

Portanto, um fato ou artefato constituiu-se em caixa preta mediante retórica. A retórica tem o poder de validar ou invalidar fatos (Latour, 2000) e, até mesmo, conduzir à adoção ou abandono de ferramentas gerenciais (Berland et al., 2010). Apesar de ciência ser o oposto de retórica, chega a um ponto em que a própria ciência se transforma em retórica (Latour, 2000).

A mediação também tem significado de delegação. Quando uma técnica é desenvolvida, os 'criadores' deram um significado, uma função para ela. Porém, tais indivíduos não estão presentes quando na sua utilização para dizer qual(is) o(s) objetivo(s) que eles atribuíram à técnica específica. Sendo assim, a técnica na sua utilização assumirá o significado que surge da articulação entre ela e o usuário (Latour, 2001).

Latour (2001, p. 213) pontua que "as técnicas, porém, modificam a substância de nossa expressão e não apenas a sua forma. As técnicas têm significado, mas produzem significado graças a um tipo especial de articulação .... Em outras palavras, mesmo as técnicas mais simples são sociotécnicas. Com esta concepção, os objetos (não humanos) passam a não ter uma natureza (essência), e os humanos deixam de ser atribuídos como puramente sociais. Assim, sujeito e objeto deixam de ser uma dicotomia com fronteiras bem delimitadas. Ao invés da visão do sujeito (humano), desconectado dos demais elementos do social para impor ordem com base na natureza, tem-se que "um coletivo sob uma dada definição pode modificar a sua composição por meio da articulação de diferentes associações" (Latour, 2001, p. 194).

Por outro lado, o rastreamento de relações, por meio de mediações e combinando interesses diferentes pode ser feito pelos objetos de delimitação (boundary object). Isso faz com que tal conceito, boundary object, seja amplamente empregado nas pesquisas baseadas na TAR. Os objetos de delimitação são, ao mesmo tempo, suficientemente plásticos para se adaptarem e autênticos (arraigados), o que mantém a similaridade entre os locais (Star \& Griesemer, 1989).

Já o conceito de porta-voz explicita "alguém que fala em lugar do que não fala" (Latour, 2000. p. 119), ou seja, indivíduos que ganham o status como representantes de outros. Os porta-vozes acabam, de alguma forma, assumindo uma hierarquia de poder em alguma instância, a fim de se legitimar como representantes de outros (Hui, 2012).

Ao redefinir subjetivo e objetivo, Latour (2001) apresenta uma alternativa ao mito do progresso. Mito, pois a certeza de que o futuro será diferente do passado é dada pelo já conhecimento adquirido dos elementos objetivos e subjetivos, resultando na sua separação. No entanto, diante da instabilidade e do contínuo crescimento de conexões entre humanos e não humanos, as segregações vistas no passado não se repetem no futuro. Pelo contrário, cada vez mais humanos e não humanos se tornam híbridos.

Sintetizando os conceitos descritos até aqui, uma rede é composta por atores humanos e não humanos, cuja interação constrói um senso coletivo do que é aceitável, válido e tenderá a permanecer. O sucesso dessa rede depende do contexto, no sentido de ter elementos que irão trabalhar pela manutenção da rede, e da institucionalização, ou seja, quanto mais enraizados estão os participantes e eventos da rede, há uma tendência a que ela permaneça e se desenvolva. A interação entre os 
agentes (translação) e a influência do poder (porta-voz) também possuem influência significativa para a manutenção da rede.

\subsubsection{Estudos anteriores sobre GEC e TAR}

ATAR tem influenciado as pesquisas em contabilidade com estudos etnográficos ou historiográficos (Justesen \& Mouritsen, 2011). Segundo Robson (1992), o potencial que a contabilidade tem de atuar como inscrição estaria no material gráfico que compõe o reporte contábil: escrita, números, listas, tabelas etc. Assim, o que o autor chama de a metáfora do número na contabilidade está relacionado à necessidade de exercer controle à longa distância por quem dela faz uso. Tais utilizações acionam o processo de translação, aumentando o alcance e sucesso da rede.

Callon e Muniesa (2005) consideram que, mesmo que sejam contestadas, as translações em contabilidade dependem mais da legitimidade dos números contábeis, ou seja, não da quantificação propriamente dita, mas do alinhamento a mecanismos retóricos para assegurar tal legitimidade. A retórica pode até ter mais espaço do que o instrumento em si.

Na sequência são apresentados alguns estudos já realizados com foco em temas relacionados à GEC utilizando a abordagem proposta pela TAR. Vale destacar que a GEC, como mencionado na seção 1, pode ser compreendida como um conceito global, que indica princípios para gestão, ou por meio de seus artefatos, ou seja, pelas ferramentas gerenciais que fazem parte do seu arcabouço. A maior parte dos estudos encontrados analisa a GEC e a TAR a partir dos artefatos.

Por exemplo, no estudo de Briers e Chua (2001), o método ABC é um objeto de delimitação que auxilia a conexão entre atores de mundos diferentes, ou seja, facilita a atuação da rede mesmo à distância. Na conclusão do trabalho, fica claro que adoções cíclicas de ferramentas gerenciais e o eventual abandono de diferentes tecnologias de custeio não são fruto de um exercício de avaliação custo-benefício cuidadoso. Assim, as novas tecnologias contábeis acabam sendo adotadas por crenças e mecanismos retóricos, de uma forma temporária e, posteriormente, são abandonadas.

Outro estudo interessante, também sobre o ABC, é o de Jones e Dugdale (2002). O artigo explora a ascensão da ferramenta com base na TAR. Na metodologia, os autores seguem os atores-chave e seus intermediários, e delineiam como eles constroem o $A B C$ por meio de uma rede de aliados humanos $\mathrm{e}$ não humanos. Nesse contexto, o $A B C$ aparece como um sistema pericial sóciotécnico que é formado mutuamente com a construção das redes de atores que o criam. Sendo um sistema especialista, o ABC é ao mesmo tempo uma resposta e um contribuinte do meio. Usando a abordagem de Callon (1991), os autores afirmam que a rede se compõe de atores e intermediários, sendo esses últimos algo ou alguém que passe entre os atores e defina a relação entre eles.

Para achar indícios do ABC, Jones e Dugdale (2002) escolhem um ator para seguir: Kaplan. Em seguida, analisam a rede de Harvard e do CAM-I. Segundo os autores, as práticas do ABC foram sendo disseminadas pelos atores nos principais journals acadêmicos da área. Enquanto isso, vários outros atores foram se interessando pelo $A B C$. As ideias também logo atravessaram o oceano e tiveram aderência no Reino Unido. Lá eles não encontraram oposição, e logo ganharam aliados, como o CIMA e outros acadêmicos. Eles afirmam que:

"o início de 1990 é um momento em que os consultores de gestão estão com fome de novos conceitos para vender. A década de 1980 viu ondas de filosofias de gestão - JIT (Just in Time), TQM (Total Quality Management), TCO (Total Cost of Ownership), fabricação de classe mundial, produção enxuta ..." (Jones \& Dugdale, 2002, p. 150).

Isto se reflete na disseminação do conceito na rede.

Além dos atores humanos, cujo papel foi essencial na criação da rede e disseminação dos conceitos, 
eles também destacam o papel do computador, por meio de um software, que de alguma forma se tornou uma caixa-preta no que diz respeito à tecnologia relacionada à CG. Uma última justificativa para a ascensão do $A B C$ se refere a um diagnóstico mais amplo, relacionado às mudanças globais, cuja produção e os mercados necessitavam de prescrições de práticas gerenciais que pudessem ser adotadas, respondendo a essas novas demandas.

Emsley (2008) usou os conceitos de translação e boundary object para o custo da qualidade. Nessa pesquisa, o custo da qualidade de Juran foi introduzido em duas plantas de manufatura de uma mesma organização do ramo químico. No entanto, elas desenvolveram o custo da qualidade por caminhos diferentes, apesar do fato de a intenção inicial ser replicar o custo da qualidade de uma planta para outra. Comentando sobre as implicações práticas do estudo, o autor conclui que técnicas, como o custo da qualidade de Juran não são fixas, nem deveriam ser implementadas em função da moda. Para gerenciar o processo de inovação mais adequadamente, os profissionais precisam entender a heterogeneidade dos interesses dos atores, a complexidade do contexto e a natureza iterativa do processo de inovação. Translação do custo da qualidade não é um processo racional nem tão pouco um processo sequencial bem definido.

Os interesses heterogêneos dos atores foram importantes por constituírem o que mais influenciou o modo como eles traduziram o custo da qualidade em cada uma das plantas. O fato de o conceito ter sido interpretado de forma diferente em cada planta e também ter outra concepção em relação à teoria de onde se originou (o custo da qualidade de Juran) corrobora os achados de Qu (2006) e Alcouffe et al. (2008): o movimento da rede faz toda a diferença na forma como o conceito original é interpretado e abordado na prática.

Retomando o estudo de Alcouffe et al. (2008), os autores procuraram entender a natureza da mudança contábil, usando como principal o conceito de translação. Foram estudados os métodos: Georges Perrin Method (GPM) e Activity Based Costing (ABC), olhando principalmente a difusão desses processos de inovação na França.

O processo de translação seguiu as quatro etapas propostas por Callon (1986), de onde eles concluem que a mudança contábil não é pré-determinada, mas pode fazer diversos movimentos de avanço ou retrocesso e de reformulações retóricas. A pesquisa explorou como controvérsias locais interferem na globalização e dificultam o processo de normalização/homogeneização das práticas de CG. Com isso, eles colocam algumas questões argumentando que pouco se conhece sobre como os caminhos da CG se movem no tempo e no espaço. Do ponto de vista da TAR, movimentos de tempo/ espaço e translações estão interligados. Não podem se movimentar sem alguma adaptação/translação e vice-versa. Ainda, qualquer difusão em tempo e espaço é um paradoxo, pois o seu resultado leva tanto a práticas homogêneas quanto heterogêneas.

Joannides e Berland (2013) colocam que as publicações construídas sob a ótica da TAR, de forma geral, em Contabilidade, se dividem em três grupos: (1) Os que estudam os papéis desempenhados pelas tecnologias contábeis dentro das organizações, quando já chegaram ao status de caixa-preta, estando mais interessados em como elas podem agir à distância por meio das inscrições; (2) Os que estudam como as inovações de CG são produzidas, alteradas e disseminadas; e (3) Os que visam entender como os métodos e referenciais teóricos empregados na pesquisa contábil servem de dispositivos retóricos que visam persuadir o público dentro da disciplina.

Dos trabalhos analisados, alguns estão diretamente relacionados à GEC. Briers e Chua (2001) e Jones e Dugdale (2002) se enquadram no primeiro grupo, ao analisar a aplicação do $A B C$ dentro do contexto organizacional. Emsley (2008) também se insere nesse grupo, porém observando o Custo da qualidade em duas plantas de uma mesma empresa.

Já Alcouffe et al. (2008) se enquadraria no segundo grupo, ao comparar o ABC com o GPM 
visando identificar seu sucesso na França, o que naturalmente inclui seus mecanismos de produção, alteração e disseminação. Notadamente, estudos focados nesse segundo grupo podem trazer potenciais contribuições ao estudo da GEC. Não foram encontrados trabalhos especificamente de GEC relacionados ao terceiro grupo, o que também aponta para possibilidades de pesquisa.

O quadro a seguir sintetiza os principais achados com a ajuda da TAR nos trabalhos que pesquisaram GEC sob esta abordagem.

Quadro 1: Principais pesquisas de GEC que utilizam a TAR

\begin{tabular}{|c|c|c|}
\hline Artigo & Tema do estudo & Principais conclusōes utilizando a TAR \\
\hline Mouritsen (1999) & $\begin{array}{l}\text { Estudo de caso sobre ferramentas gerenciais em } \\
\text { uma organização (entre elas, as de custos) }\end{array}$ & $\begin{array}{l}\text { Mostra a construção retórica para a sedimentação } \\
\text { da rede, utilizando como meio as ferramentas } \\
\text { gerenciais (controles gerenciais, gestâo de custos } \\
\text { e inovação). }\end{array}$ \\
\hline Jones e Dugdale (2000) & $\begin{array}{l}\text { ABC e TOC (Theory of Constraints) como sistemas } \\
\text { sociotécnicos. }\end{array}$ & $\begin{array}{l}\text { Descrição da formação de alianças que compōe a } \\
\text { rede. Papel relevante dos consultores e softtares } \\
\text { na disseminação das ferramentas, bem como papel } \\
\text { secundário da academia. Construçãa retórica para } \\
\text { nova roupagem de sistemasa anteriores, ou seja, } \\
\text { as ferramentas foram "vendidas" como inovaçăo, } \\
\text { quando na verdade possuem forte inspiração em } \\
\text { ferramentas já existentes. }\end{array}$ \\
\hline Briers e Chua (2001) & Influência da rede na implantação do $A B C$ & $\begin{array}{l}\text { A construção retórica influencia o processo de } \\
\text { adoção e abandono dos artefatos, como o ABC. }\end{array}$ \\
\hline Jones e Dugdale (2002) & Implantação e ascensão do $\mathrm{ABC}$ & $\begin{array}{l}\text { Reconstrução da rede por meio de atores (humanos } \\
\text { enão humanos). Influência da tecnologia contábil } \\
\text { (ABC) na construção da rede, ao mesmo tempo } \\
\text { em que o ABC é disseminado pela própria rede. } \\
\text { Influência das autoridades (Kaplan, Cooper, CAM-I } \\
\text { etc.) no processo de disseminação da ferramenta. } \\
\text { Descriçăoo do processo de mediação (translação) } \\
\text { entre os participantes. Influência dos journals } \\
\text { acadêmicos e dos softwares no processo de } \\
\text { disseminação do ABC. }\end{array}$ \\
\hline Alcouffe et al. (2008) & $\begin{array}{l}\text { Implantação de mudanças contábeis e processos de } \\
\text { inovação utilizando as ferramentas: Georges Perrin } \\
\text { Method (GPM) e Activity Based Costing (ABC) }\end{array}$ & $\begin{array}{l}\text { O processo de translação mostrou que a mudança } \\
\text { contábil não é pré-determinada, mas pode fazer } \\
\text { diversos movimentos deavanço ou retrocesso e de } \\
\text { reformulaçoes retóricas. Influência de consultores, } \\
\text { editores de softwares e acadêmicos no processo de } \\
\text { validaçăo e disseminacaáo das ferramentas. GPM } \\
\text { teve menor suporte de atores, ao contrário do } \\
\text { ABC, o que influenciou na difusão e perenidade } \\
\text { de cada método. }\end{array}$ \\
\hline Emsley (2008) & $\begin{array}{l}\text { Implantação do custo da qualidade em duas plantas } \\
\text { de uma mesma empresa }\end{array}$ & $\begin{array}{l}\text { Compreensão da heterogeneidade dos interesses } \\
\text { dos atores, da complexidade do contexto e da } \\
\text { natureza iterativa do processo de inovação. A } \\
\text { TAR forneceu melhor suporte pelo conceito de } \\
\text { translação do que a teoria da contingência para } \\
\text { compreender o caso. Como os participantes de } \\
\text { cada planta eram diferentes, a ferramenta foi } \\
\text { implantada de forma distinta entre as plantas } \\
\text { (mesmo não sendo essa a ideia inicial). Os } \\
\text { interesses distintos dos atores foram importantes } \\
\text { por constituírem o que mais influenciou o modo } \\
\text { como os atores traduziram o custo da qualidade } \\
\text { em cada uma das plantas. }\end{array}$ \\
\hline
\end{tabular}

Fonte: dos autores.

O objetivo desta seção foi dar base aos principais temas envolvidos neste estudo, a fim de potencializar as discussões que serão abordadas a seguir. É importante destacar sobre a GEC que há diferentes concepções entre os autores pesquisados em relação ao seu conceito, bem como os estudos analisados em sua maioria corroboram as preocupações de Shank (2006) sobre o estágio de evolução da área. Sobre a TAR, configura-se como uma teoria dotada de conceitos práticos que favorecem a compreensão da rede, seja qual for o campo de estudos analisado. Estudos envolvendo GEC eTAR foram realizados utilizando os artefatos da GEC e, em sua maioria, mostram a influência da movimentação da rede e da retórica na construção do campo científico.

\section{PARADOXO DA GEC}

A esta altura, é possível discutir o que neste artigo é chamado de paradoxo da GEC, ou seja, entender porque a GEC parece diminuir em termos de atuação e visibilidade, apesar da sua importância para a competitividade das empresas no meio empresarial.

Segundo El-Dyasty (2007), as técnicas tradicionais de custos estão mais voltadas à mensuração 
e controle de custos de produtos e serviços e não são suficientes para lidar com os novos desenvolvimentos econômicos e tecnológicos. Outros trabalhos demonstram que a GEC não dispõe de uma estrutura teórica consistente, estando ainda na sua infância (El Kelety, 2006), além de não ter sido muito utilizada fora da contabilidade (Ellram \& Stanley, 2008) e de, nas empresas, predominarem as medidas operacionais de custos, sem alcance da estratégia (Chenhall, 2008; Ernst\&Young \& IMA, 2003; Heckmann, Konik, Samakh, \& Weissbarth, 2009).

Como já mencionado, Shank (2006) foi crítico em sua reflexão sobre a GEC. Nela são realizadas afirmações que poderiam explicar o porquê da não expansão do tema nos meios acadêmico e organizacional.

O autor coloca que o assunto teve sua contribuição seminal dada por Simmonds no ano de 1981, tendo sido os anos 1990 a década gloriosa, na qual surgiram os primeiros estudos de caso, aplicações piloto em empresas e difusão dos conceitos relacionados à GEC em consultorias e firmas especializadas. Mesmo nesse período, notou-se que as práticas gerenciais em ascensão não tinham sua correspondente aplicação e análise em journals de impacto, de forma que os assuntos tratados não compuseram o mainstream dos livros-texto, tampouco a teoria ou as principais searas do mundo corporativo.

Outro ponto notado foi que, no início, as aplicações de GEC nas organizações cresciam sem envolvimento dos contadores-gerenciais, o que, de certa forma, na visão do autor, demonstra falta de habilidade e perfil dos contadores com os novos temas empreendidos, além de certo despreparo frente à mudança requerida do profissional para lidar com esses assuntos, dando a entender a importância dos participantes do processo para a efetivação do mesmo.

$\mathrm{Na}$ década seguinte, ele comenta que é possível observar que as associações de contadores gerenciais, de forma geral, não prosperaram. Nos periódicos acadêmicos, poucos artigos haviam sido publicados com temas relacionados à GEC. Percebia-se também um declínio no currículo de CG, com predominância mais aos temas de controle gerencial, mais operacionais, em detrimento aos de suporte à tomada de decisão, mais estratégicos, na visão do autor. Da mesma forma, periódicos importantes da área não costumavam publicar trabalhos sobre tais temas, o que incluía a GEC.

Paralelamente, Shank (2006) coloca que as consultorias e firmas especializadas passaram a dar ênfase em temas relacionados à tecnologia da informação e ao suporte regulatório, tendo sido, por exemplo, os ERPs vendidos como ferramenta para tomada de decisão, embora, na prática, servissem de apoio para o processamento de transações. Ainda, os escândalos contábeis ocorridos no início dos anos 2000 fizeram com que os esforços fossem redirecionados da Contabilidade Gerencial para temas relacionados à prevenção e detecção de fraudes e controles, ou seja, atenção maior passou a ser direcionada à Contabilidade Financeira.

O autor comenta que, nas empresas, o número de profissionais voltados à CG tem diminuído, fazendo com que a informação de custos seja vista apenas como um subproduto dos ERPs em muitas delas. Ademais, dos profissionais remanescentes, boa parte do tempo é tomado com questões relacionadas a risco e fraudes, como a Lei Sarbanes-Oxley. Na academia, segundo o autor, o número de journals importantes da área de custos tem se restringido. Profissionalmente, ele comenta que praticamente não existem associações que promovam o assunto, o que reforça ainda mais seu argumento de que a CG não tem prioridade nas organizações, perdendo espaço para itens mais técnicos, como os padrões contábeis advindos da Contabilidade Financeira. Nas organizações, a visão que se tem é da contabilidade como um fim em si mesma, e não como uma ferramenta para a gestão do negócio. A informação gerencial acaba sendo fornecida por analistas de formações distintas, fazendo com que as rotinas de CG estejam mais relacionadas ao suporte e ERPs, e não a ser uma ferramenta de gestão estratégica. 
Sintetizando, o autor comenta que é mais fácil para professores e contadores gerenciais desconsiderarem a complexidade que envolve a inclusão da estratégia no ensino de conceitos de custos. Logo, há pouca multidisciplinaridade e integração nos conteúdos.

Olhando a situação por outra perspectiva, mais um olhar crítico é o de Chua (2011) que, em resposta à argumentação de Ohlson (2011), procurou discutir a ideia de uma pesquisa contábil bem sucedida. Ela coloca que, em geral, falta na pesquisa contrapor as ideias ao método. Faltam, também, profundas e fortes conexões com a prática.

Baseado na perspectiva de Latour, a autora utiliza a visão da TAR para exemplificar sua fala, a fim de mostrar que as redes determinam o que será considerado uma pesquisa bem sucedida. Segundo ela, o sucesso está nas mãos de outros e há um limite para o quanto o pesquisador individualmente pode, de fato, causar influência por meio de seu trabalho, por existirem restrições institucionalizadas (Latour, 2000). Sob esse ponto de vista, ela argumenta que o processo do que é verdade em um meio depende do convencimento de cientistas relevantes da área. Logo, o sucesso é um exercício de persuasão crescente (Chua, 2011). Nesse sentido, o sucesso da rede advém de uma construção retórica com base em evidências, autoridade, moda, lógica etc., utilizados para desenvolvimento e manutenção da rede.

Dentro da visão da Teoria Ator-Rede, Chua (2011) pontua alguns exemplos de entidades ou elementos, tanto humanos quanto não humanos, que se pronunciam sobre a validade, valor e confiabilidade, nesse caso, da pesquisa. Por exemplo, humanos - revisores e editores; e não humanos algoritmos (como o fator de impacto), técnicas de classificação, tecnologias de contagem etc.

Para a autora, na pesquisa em contabilidade não existe apenas o ramo econômico-financeiro contrário ao que é enfatizado no trabalho analisado (Ohlson, 2011). Sintetizando o pensamento dela, há prejuízo para a contabilidade enquanto os pesquisadores da área se restringirem às perspectivas ou métodos direcionados aos principais journals. A ausência de diversidade produz menor abertura a algumas linhas de pesquisa e isso repercute em toda a comunidade acadêmica.

Olhar a GEC como campo científico, seja concebendo-a por meio dos seus princípios e/ou de seus artefatos, passa por compreender, conforme a abordagem de Chua (2011), a influência que atores, softwares, journals, autoridades, entre outros, têm tido para o processo de construção do campo. Nesse sentido, os conceitos da TAR auxiliam a melhor entender que o senso comum, na verdade, é produto de muito trabalho realizado por todos os participantes a serem considerados nessa rede (Chua, 2011).

Até aqui, fazendo convergir as visões de Chua (2011) e Shank (2006), a perspectiva da rede que influencia a CG e, especificamente, a GEC, pode auxiliar a verificar os fatores analisados por Shank (2006).

A preocupação com a existência de um corpo teórico consolidado sobre GEC e com as implicações práticas que envolvem a Gestão Estratégica de Custos não foi alvo somente das reflexões de Shank (2006), mas motivou diversos trabalhos, que deram origem a uma relação de argumentos sintetizados a seguir: profissionais de contabilidade tem dificuldades na implementação de iniciativas estratégicas de gestão de custos (Ernst\&Young \& IMA, 2003); muitas organizações, ainda que de grande porte, tendem a utilizar ferramentas tradicionais para a gestão de custos (Ernst\&Young \& IMA, 2003; Dugdale, Jones, \& Green, 2006); os estudos existentes sobre GEC ainda estão em fase exploratória e não há um corpo conceitual consolidado (El Kelety, 2006); não há envolvimento de contadores gerenciais com as práticas de custos (Anderson, 2006; Shank, 2006); o corpo de conhecimentos que compõe a GEC não está preponderantemente relacionado à CG, mas sim, a outras áreas, como Gestão de Operações, Tecnologia da Informação e Administração Geral, fato que questiona o modo como a CG pode ser percebida estrategicamente (Anderson, 2006; Chenhall, 2008); e a GEC é encontrada somente na literatura contábil (Ellram \& Stanley, 2008).

Pode-se traçar um paralelo em relação a essas ideias com o pensamento de Latour (2000, p. 171), 
de que "a construção dos fatos ... é um processo coletivo". Na visão do autor, é necessário "alistar outras pessoas" para que elas participem da construção do fato científico. Porém, os fatos são resultado de interações entre a rede de agentes humanos e não humanos: "Nunca estamos diante de 'ciência, tecnologia e sociedade', mas sim de uma gama de associações mais fortes e mais fracas" (Latour, 2000, p. 232).

Retomando os pontos principais colocados, tem-se, de um lado, um corpo de conhecimentos da Gestão Estratégica de Custos, envolvido por controvérsias quanto a sua profundidade teórica e aplicação/difusão prática. Tal temática, supostamente, favorece a gestão no que tange a ampliar a competitividade das empresas, no entanto, supostamente sem relevância percebida no meio, como foi descrito. De outro lado, encontra-se o estudo de redes, mais especificamente a Teoria Ator-Rede, que mostra como o coletivo pode ser construído por meio da movimentação de diversos atores, humanos e não humanos. Fica evidente a importância de se compreender a forma como esses agentes vêm se mobilizando na construção da GEC.

\section{DISCUSSÃO}

Este estudo objetiva discutir o aparente paradoxo de não implementação na GEC na sua totalidade, ou seja, de uma formação incompleta da rede envolvida, diante da necessidade de tecnologias de avaliação de desempenho para enfrentar a competividade. Para isso, emprega conceitos da Teoria do Ator Rede para gerar algumas proposições.

O processo de continuidade discutido pelos teóricos da TAR pressupõe que programas de ação sejam empreendidos. Tais programas irão garantir o sucesso de um artefato, modelo de negócio etc., bem como ser objeto de diversas translações, conectando atores e interesses de diferentes mundos. Jones e Dugdale (2002), por exemplo, pontuam que os consultores de Harvard e o CAM-I tinham distintos interesses: enquanto os primeiros estavam preocupados com as propostas de implantação do $A B C$, o CAM-I buscava construir sistemas de custeio inovadores em organizações de grande porte; o que faz com que os primeiros se concentrem no desenvolvimento de softwares, enquanto o CAM-I usa o $A B C$ apenas como uma métrica para medir o desempenho. Com isso, pode-se deduzir a seguinte proposição: (1) No processo de implantação da GEC emergem atores cuja oferta não é simétrica com os objetivos dos demais atores.

Outro ponto a ser analisado é a simetria entre os agentes. Jones e Dugdale (2002) constataram que havia divergência, por exemplo, entre as abordagens de Cooper e Kaplan para a abordagem proposta por Johnson, e ainda, a mudança de escopo e de abordagem do CAM-I durante o processo (Jones, \& Dugdale, 2002). Emsley (2008) afirma que os distintos interesses dos agentes envolvidos dificultou a implantação do custeio da qualidade nas duas plantas da empresa estudada. Com isso, pode-se formular a segunda proposição: (2) Na ausência de simetria entre os agentes, não foram construídos subprogramas. No escopo da TAR, conforme discutido, existe o conceito de caixa preta, em que ideias, documentos, declarações são compostos e geram uma filosofia, tal como a GEC. Diante das controvérsias, ao invés de abrir a caixa preta, neste caso a GEC, as "pessoas começam usar textos, arquivos, documentos e artigos para forçar outras pessoas a transformar o que de início era uma opinião em um fato" (Latour, 2000, p. 54).

O mundo acadêmico é pulverizado por retórica. Livros-texto, modelos, e artigos já constituídos de sucessivas declarações que passam a ser consideradas 'verdades.' Emsley (2008) afirma que durante o processo de implantação do custeio da qualidade, algumas situações envolviam intenso debate entre 
os envolvidos até que pudessem ser estáveis o suficiente para se tornarem caixas-pretas. Jones e Dugdale (2000) colocam que o ABC e oTOC nada mais são do que remodelagens de antigas métricas de custeio de meados do século XX, fortemente influenciadas pela retórica de seus porta-vozes. Alchouffe et al. (2008) também endossam a proposição ao afirmarem que as mudanças no ambiente contábil são provenientes de formulações retóricas, de forma que a estabilidade é construída pelos próprios atores. Dessa forma, surge a terceira proposição: (3) A GEC tornou-se uma caixa preta induzida por retórica. A caixa-preta é um fato ou objeto que, por ter alcançado um nível de êxito, não é mais passível de contestação. Necessita do processo ativo da rede para sua continuidade (Latour, 2000, 2001). Todas as inscrições podem se tornar caixas-pretas, no entanto, o baixo nível de adoção pode levar ao seu desuso ou declínio. No caso da GEC, isso pode ocorrer na implantação de qualquer artefato (Alcouffe et al., 2008).

O coletivo, por sua vez, é que determina o que é tido como verdade em um meio, sendo efetivado por meio da retórica, que reforça ou invalida os fatos ( Latour, 2000, 2001, 2004; Chua, 2011). A percepção do coletivo, no caso dos atores humanos, é influenciada pelo contexto, que na GEC pode estar relacionado ao ambiente físico (empresa), geográfico (país) ou a mecanismos de crenças e valores. Também sofre influência dos processos retóricos promovidos pelos atores sobre, por exemplo, melhores práticas que devem ser adotadas por uma organização (Mouritsen, 1999; Briers \& Chua, 2001). A última proposição colocada neste estudo aborda a continuidade (ou não) da rede, sendo: (4) Para entender como se deu a (des)continuidade da GEC enquanto rede, é preciso entender as delegações que emergiram nas associações entre humanos e não humanos. As idas e vindas do processo de construção retórica é que formam (ou não) a estabilidade da rede (Alchouffe et al., 2008).

A rede é o meio de ação composto pelos atores humanos e não humanos. Sua construção, ou seja, os papéis desempenhados pelos envolvidos determinam quais processos e conceitos terão sucesso. A rede precisa continuar a atuar para manter os processos que encabeça. Ela também dá subsídio aos mecanismos de ação à distância (Latour, 2000; Chua, 2011). O insucesso na disseminação de conceitos contemporâneos da GEC (por exemplo, profissionais que não conhecem tais práticas) pode ser devido a falhas nos processos de construção ou manutenção da rede (Alcouffe et al., 2008; Emsley, 2008).

Os porta-vozes são representantes de outras partes junto à rede (Latour, 2000). Possivelmente, por algum tempo, os atores engajados na GEC representaram vozes de organizações, estudantes e profissionais ávidos por mudanças e novos mecanismos que solucionassem suas demandas. À medida que tais demandas se transformam, novos representantes surgem. Tais representantes em geral representam argumentos de autoridade de pessoas ou instituições proeminentes no meio (Jones \& Dugdale, 2002). Em outras palavras, é possível que em algum ponto do tempo, os atores engajados na GEC tenham perdido sua representatividade, por exemplo, pela não existência de associações profissionais ou pela mudança das necessidades organizacionais, não acompanhadas pela área.

A translação determina significados e estabelece os processos de mudança, além de relações, mecanismos de poder e representação na rede, conforme os interesses dos atores. As alianças produzidas nesse processo é que irão garantir o sucesso da rede. Ela também determina quais atores irão permanecer (Callon, 1986; Latour, 2000, 2001; Hui, 2012). As alianças entre atores humanos e sedimentação dos não humanos são fruto de processos de translação. Considerando as quatro etapas do processo, o despertar de interesse por um tema, somado ao estabelecimento de papéis e definição de alianças, bem como ao uso de tecnologias para sedimentar tais tentativas, é que se pode determinar a efetividade de um processo de translação. Quando uma ferramenta não chega sequer a ser institucionalizada, possivelmente uma das etapas do processo de translação não logrou êxito (Jones \& Dugdale, 2002; Alcouffe et al., 2008; Emsley, 2008). 
Os trabalhos consultados mostram que a implantação de um artefato de GEC se deve, em geral, a mecanismos de construção preponderantemente baseados na retórica. Para que a técnica gerencial utilizada seja efetiva, é necessária uma grande movimentação da rede, muitas vezes extrapolando os limites organizacionais, tendo em vista a importância descrita de elementos externos como consultores, pesquisadores e, até mesmo, softwares e periódicos. Os argumentos de autoridade também auxiliam a reforçar a construção retórica. E, da mesma forma que tal construção culmina na implantação, o abandono também expressa um processo de menor convergência entre os mais diversos interesses dos participantes da rede. Tal processo é de fato complexo, por envolver uma gama distinta de atores e argumentos, além de poder se estender ao longo de anos.

Ademais, a despeito de tantas idas e vindas de uma imensa gama de artefatos, distintos interesses e um intenso processo retórico, a GEC parece falhar na intenção de ser um novo paradigma para a gestão (Shank, 1989), por ter dificuldade de incorporar a complexidade do meio em seus modelos e artefatos previamente estabelecidos. Tal situação pode, de alguma forma, reforçar a necessidade da construção retórica. A TAR entende que a complexidade do meio não pode ser colocada em sistemas e modelos, justamente por seu caráter de alteração contínua e heterogeneidade.

Ao observar o fenômeno de estudo, que se refere à evolução da GEC como área do conhecimento, tanto teórica quanto prática, a TAR traz subsídios para a compreensão de quem são os agentes de maior influência neste processo, bem como, de que maneira ocorrem os eventos que concebem, alteram e referendam a GEC como área de conhecimento e sua rede de atores. Ainda, é possível compreender os mecanismos que levam à total institucionalização, legitimidade ou mesmo ao abandono de suas ferramentas, um passo anterior ao que geralmente fazem os estudos dessa área quando utilizam outras teorias para constatar a institucionalização (ou não) de um artefato em uma organização.

\section{CONSIDERAÇÕES FINAIS}

Neste estudo discutiu-se o aparente paradoxo que envolve a inércia da GEC como instrumento gerencial e área de pesquisa e a eminente demanda de sua adoção. Com a concepção de que a contabilidade faz parte de um ambiente complexo, compreender o dilema posto exige conceitos que dão suporte à análise de construção das estruturas sociais, neste estudo da Teoria do Ator-Rede.

A situação representada pelo paradoxo pode ser explicada pela forma como os profissionais e acadêmicos veem os instrumentais da GEC. Eles poderiam estar sendo vistos como prontos, ou seja, caixas-pretas, e negligenciar que a sua função ocorre por meio da associação com outros atores. A GEC poderia estar sendo vista assimetricamente. Há que se ponderar que a construção da GEC depende fundamentalmente da movimentação da rede, preponderantemente em cima de uma construção retórica, bastante influenciada por argumentos de autoridade como consultores e acadêmicos, e disseminada por meio de softwares e publicações.

Porém, o ponto mais crucial e talvez também mais polêmico que a TAR proporciona para compreender o paradoxo discutido está na essência atribuída à GEC de ser uma filosofia munida de técnicas que ajuda a nortear a definição do futuro da empresa. A TAR, por meio dos seus conceitos, mostra a complexidade e instabilidade na construção da realidade. A capacidade da GEC de contribuir estrategicamente vai depender do contexto em que ocorrem os entrelaçamentos dos atores envolvidos nas diversas associações existentes. Sendo assim, é possível concluir que a função de contribuir para decisões futuras não é intrínseca às técnicas da GEC, mas poderá se manifestar ou não dependendo das associações feitas e dos interesses dos agentes envolvidos. Em outras palavras, a construção retórica di- 
sseminada pela rede, bem como seus meios de propagação, são determinantes para o desenvolvimento do campo científico.

Se estudos apontam uma diminuição de crescimento da área ao mesmo tempo em que se entende o processo de construção da rede, pode-se colocar que, de alguma forma, a construção retórica ou os interesses dos agentes envolvidos nesta rede tem direcionado para outros caminhos, o que impacta no paradoxo que vem sendo construído. Algumas perguntas surgem: é possível desenhar tais associações ao ponto que se detecte quais as combinações que resultam no sucesso de implantação da GEC? Seriam as tecnologias da GEC sólidas demais que não se adaptariam? Existem situações em que elas não se configuram em objetos de delimitação?

A GEC como área de pesquisa poderia estar ameaçada pela sua dificuldade em se inserir num coletivo ou de se construir esse coletivo, movimento construído basicamente por mecanismos retóricos (Latour, 2000; Callon \& Muniesa, 2005), angariando baixa visibilidade e convergência aos participantes da rede (Callon, 1991).

O próximo passo a essa pesquisa, aqui tido como sugestão de estudos futuros, é usar esse ferramental para efetivar pesquisas empíricas buscando as questões elencadas. Ademais, entende-se que o estudo proposto pela TAR pode ser aplicado a outras áreas que envolvam a CG, dada a semelhança entre os fenômenos da matéria.

\section{REFERÊNCIAS}

Afonso, P. S. L. P. (2007). Modelling the intertwined roles of institutional and technical environments in Management Accounting change (Doctoral Thesis). University of Manchester.

Alcouffe, S., Berland, N., \& Levant, Y. (2008). Actor-networks and the diffusion of management accounting innovations: a comparative study. Management Accounting Research, 19(1), pp. 1-17.

Anderson, S. W. (2006). Managing costs throughout the value chain: research on strategic cost management. Handbook of Management Accounting Research, 2(October 2005).

Anderson, S. W., \& Dekker, H. C. (2009). Strategic cost management in supply chains, part 1: Structural cost management. Accounting Horizons, 23(2), 201-220. http://doi.org/10.2308/acch.2009.23.2.201

Baxter, J., \& Chua, W. F. (2003). Alternative management accounting research - whence and whither. Accounting, Organizations and Society, 28(2-3), pp. 97-126.

Berland, N., Joannides, V., \& Levant, Y. (2010). Institutionalisation and deinstitutionalisation of budget. In European Accounting Association Congress.

Bhimani, A., \& Gosselin, M. (2009). Cost management diversity in a global world: what we can learn? Cost Management, 23(5), pp. 29-33.

Bjørnenak, T. (2000). Understanding cost differences in the public sector- a cost drivers approach. Management Accounting Research, 11(2), pp. 193-211.

Bloom, N., \& Reenen, J. Van. (2010). Why do management practices differ across firms and countries? Journal of Economic Perspectives, 24(1), pp. 203-224.

Böer, G. B. (2000). Management accounting education: yesterday, today, and tomorrow. Issues in Accounting Education, 15(2), pp. 313-334.

Borges Slavov, T. N. (2013). Gestão Estratégica de Custos: uma contribuição para a construção de sua estrutura conceitual (Tese de Doutorado). Universidade de São Paulo. 
Briers, M., \& Chua, W. F. (2001). The role of actor-networks and boundary objects in management accounting change: a field study of an implementation of activity-based costing. Accounting, Organizations and Society, 26, pp. 237-269.

Callon, M. (1986). Some elements of a sociology of translation: domestication of the scallops and the fishermen of St Brieuc Bay. In Power, action and belief: a new sociology of knowledge? (Routledge, pp. 196-223). London.

Callon, M. (1991). Techno-economic networks and irreversibility. In J. Law (Ed.), A sociology of monsters: Essays on power, technology and domination. London.

Callon, M., \& Muniesa, F. (2005). Peripheral vision: economic markets as calculative collective devices. Organization Studies, 26(8), pp. 1229-1250.

Chenhall, R. H. (2008). Accounting for the horizontal organization: a review essay. Accounting, Organizations and Society, 33(4-5), pp. 517-550.

Cooper, R. (1997). What the interaction between management accounting and cost management means to CPAs in finance. Journal of Accountancy, 2-5.

Chua, W. F. (2011). In Search of "successful" accounting research. European Accounting Review, 20(1), pp. 27-39.

Demo, P. (2012). Ciência Rebelde: Para continuar aprendendo, cumpre desestruturar-se. São Paulo: Editora Atlas.

Dugdale, D., Jones, T., \& Green, S. (2006). Contemporary management accounting practices in uk manufacturing. London: CIMA Publishing.

Ekbatani, M. A., \& Sangeladji, M. A. (2008). Traditional vs. contemporary managerial/cost accounting techniques differences between opinions of educators and practitioners. International Business \& Economics Research Journal, 7(1), pp. 93-112.

El Kelety, I. A. E. M. A. (2006). Towards a conceptual framework for strategic cost management the concept, objectives, and instruments. Universitl"atsbibliothek der Technischen Universitl"at. Retrieved from http://deposit.ddb.de/cgi-bin/dokserv?idn=980955033\&amp;dok_var=d1\&amp;dok_ ext=pdf\&amp;filename=980955033.pdf

El-Dyasty, M. M. (2007). A framework to accomplish strategic cost management. SSRN Electronic Journal.

Ellram, L. M., \& Stanley, L. L. (2008). Integrating strategic cost management with a 3dce environment: strategies, practices, and benefits. Journal of Purchasing and Supply Management, 14(3), pp. 180-191.

Emsley, D. (2008). Different interpretations of a "fixed" concept: examining Juran's cost of quality from an actor-network perspective. Accounting, Auditing \& Accountability Journal, 21(3), pp. 375-397.

Ernst \&Young, \& IMA, I. of M. A. (2003). Survey of Management Accounting.

Gao, P. (2005). Using actor-network theory to analyse strategy formulation. Information Systems Journal, 15(3), pp. 255-275.

Heckmann, P., Konik, F., Samakh, E., \& Weissbarth, R. (2009). Restructuring in 2009 understanding and responding to the crisis.

Hoffjan, A., \& Wompener, A. (2006). Comparative analysis of strategic management accounting in german and english language general management accounting textbooks. Schmalenbach Business Review, 58(July), pp. 234-259.

Hui, D. (2012). Actor-network theory analysis of the budgetary process in the New Zealand school sector. Auckland University of Technology. 
Ittner, C. D., \& Larcker, D. F. (2001). Assessing empirical research in managerial accounting: A value-based management perspective. Journal of Accounting and Economics, 32(1-3), pp. 349-410.

Joannides, V., \& Berland, N. (2013). Constructing a research network: accounting knowledge in production. Accounting, Auditing \& Accountability Journal, 26(4), pp. 512-538.

Johnson, H. T., \& Kaplan, R. S. (1987). Relevance lost: the rise and fall of management accounting. (H. B. S. Press, Ed.). Massachusetts.

Jones, T. C., \& Dugdale, D. (2000). The making of "New"Management Accounting: A comparative analysis of $A B C$ and TOC. In Interdisciplinary Perspectives on Accounting Conference (pp. 0-28). Manchester.

Jones, T. C., \& Dugdale, D. (2002). The ABC bandwagon and the juggernaut of modernity. Accounting, Organizations and Society, 27, pp. 121-163.

Justesen, L., \& Mouritsen, J. (2011). Effects of actor-network theory in accounting research. Accounting, Auditing \& Accountability Journal, 24(2), pp. 161-193.

Langfield-Smith, K. (2008). Strategic management accounting: how far have we come in 25 years? Accounting, Auditing \& Accountability Journal, 21(2), pp. 204-228.

Latour, B. (2000). Ciência em ação - como seguir cientistas e engenheiros sociedade afora (UNESP). São Paulo.

Latour, B. (2001). A esperança de Pandora: ensaios sobre a realidade dos estudos científicos. (EDUSC). São Paulo.

Latour, B. (2004). Whose cosmos, which cosmopolitics? - comments on the peace terms of Ulrich Beck. In Common Knowledge. Duke University Press.

Latour, B. (2005). Reassembling the Social: an introduction to actor-network-theory. New York: Oxford University Press.

Latour, B. (2006). Como terminar uma tese de sociologia: pequeno diálogo entre um aluno e seu professor (um tanto socrático). Cadernos de Campo, 14/15.

Lowe, A. (2001). After ANT - An illustrative discussion of the implications for qualitative accounting case research. Accounting, Auditing \& Accountability Journal, 14(3), pp. 327-351.

McNair, C., L. Polutnik and R. Silvi (2001). Cost management and value creation: the missing link. The European Accounting Review, 10(1), pp. 33-50.

Meira, J., Kartalis, N. D., Tsamenyi, M., \& Cullen, J. (2010). Management controls and inter-firm relationships: a review. Journal of Accounting \& Organizational Change, 6(1), pp. 149-169.

Mouritsen, J. (1999). The flexible firm - strategies for a subcontractor's management control. Accounting, Organizations and Society, 24, 31-55.

Ohlson, J. A. (2011). On Successful Research. European Accounting Review, 20(1), pp. 7-26.

Porter, M. (1985). Competitive Advantage: creating and sustaining superior performance. New York:The Free Press.

Qu, Q. (2006). The construction and customization of the Balanced Scorecard: a field study of management consultants in translating popular management accounting techniques. University of Alberta.

Robson, K. (1992). Accounting numbers as "inscription": action at a distance and the development of accounting. Accounting, Organizations and Society, 17(7), pp. 685-708. 
Shank, J. K. (2006). Strategic cost management: upsizing, downsizing, and right sizing. In A. Bhimani (Ed.), Contemporary issues in management accounting. Oxford University Press. Retrieved from http://priatakberistri.com/download/accounting/Contemporary Issues in Management Accounting. pdf\#page $=372$

Shank, J. K., \& Govindarajan, V. (1997). A revolução dos custos: como reinventar e redefinir sua estratégia de custos para crescer em mercados crescentemente competitivos. Rio de Janeiro: Elsevier.

Star, S. L.., Griesemer, J. R. (1989) Institutional ecology, 'translations' and boundary objects: amateurs and professionals in Berkeley's Museum of Vertebrate Zoology, 1907-39. Social Studies of Science, 19 (3), pp. 387-420.

Tan, L. M., Fowler, M. B., \& Hawkes, L. (2004). Management accounting curricula: striking a balance between the views of educators and practitioners. Accounting Education, 13(1), pp. 51-67.

Zawawi, N. H. M., \& Hoque, Z. (2010). Research in management accounting innovations An overview of its recent development. Qualitative Research in Accounting \& Management, 7(4), pp.505-568. 